\title{
REGULATORY EFFECT OF DOPAMINE ON SPATIAL PROPERTIES OF HORIZONTAL CELLS IN CARP RETINA ${ }^{1}$
}

\author{
TSUNENOBU TERANISHI, KOROKU NEGISHI, ${ }^{2}$ AND SATORU KATO
}

\begin{abstract}
Department of Neurophysiology, Neuroinformation Research Institute, University of Kanazawa School of Medicine, Kanazawa, Ishikawa 920, Japan
\end{abstract}

Received August 5, 1983; Revised December 12, 1983; Accepted December 13, 1983

\begin{abstract}
Three types of light-induced response (L-, RG-, and YRB-type S-potentials) recorded from isolated retinas of the carp (Cyprinus carpio) were identified by their spectral response and later by morphological localization of the recording sites marked with an intracellular Lucifer Yellow (LY). Horizontal cells in a given layer, generating one of the above response types, are electrically coupled via gap junctions, so that the injected LY normally diffused to several neighboring cells. The spatial property of the three types of responses was examined by enlarging the diameter of a light spot $(0.25$ to $4.0 \mathrm{~mm})$ and displacing the spot $(0.5 \mathrm{~mm}$ diameter $)$ along a straight $4-\mathrm{mm}$ line which passed over the recording point at the middle. In normal retinas, the half-decay distance of response amplitude with spot displacement was shorter in the order of L-, RG-, and YRB-type responses, and correspondingly the dye diffusion area was narrower in the same order of cells. Dopamine (DA; 10 to $20 \mu \mathrm{M}$ ), applied to the vitreous fluid beneath the isolated retina, altered the spatial property of all types of responses by increasing the amplitude of responses to central spots and decreasing that of those to distant spots, and it restricted the intracellular LY to single injected cells. In contrast, in retinas from which DA interplexiform cells had been deprived by prior destruction with a neurotoxin, 6-hydroxydopamine, the amplitude of responses became smaller while the half-decay distance was longer by 1.1- to 1.6-fold, depending upon the cell type, and the dye diffusion area in all types of cells became wider by 2 -fold as compared to those in normal retinas. The results indicate that DA regulates the spatial properties of all types of horizontal cells and that there is an apparent correlation between the degrees of S-potential spread (electrical coupling) and of the dye coupling among horizontal cells in a given layer.
\end{abstract}

As one of the second-order neurons, horizontal cells form two to three layers of subclasses immediately below the photoreceptor cell layer in the fish retina. Each of the subclasses generates a different type of light-induced response (S-potential) and is electrically coupled via gap junctions between cells in a given layer (Naka and Rushton, 1967; Kaneko, 1971; Marmarelis and Naka, 1972). The amplitude of S-potentials recorded from horizontal cells has been shown to increase monotonically with the enlarging area of illumination over the retinal surface (Tomita et al., 1958; Norton et al., 1968). It has been assumed that this characteristic spatial summation of Spotentials is due to a lateral spread phenomenon via gap junctions.

A fluorescent dye (Lucifer Yellow (LY)) injected into

${ }^{1}$ We wish to thank Mrs. Tami Urano for secretarial assistance. This work was supported in part by research funds from the Japan Society for the Promotion of Science, the Naito Foundation (82-128), and the Johnan Hospital in Takaoka.

${ }^{2}$ To whom correspondence should be addressed. a horizontal cell normally diffuses to several neighbc ring cells via gap junctions (Stewart, 1978; Kaneko and Stuart, 1980; Piccolino et al., 1982; Teranishi, 1983). Exogenously applied dopamine (DA) alters the spatial properties of horizontal cell responses to light, increasing in amplitude the center response to spot while decreasing the surround response to annular illumination (Negishi and Drujan, 1978, 1979). These effects result in shrinkage of the potential summation area (receptive field) of horizontal cells (Cohen and Dowling, 1983) and have been attributed to the action of DA on the membrane resistance, particularly at the gap junctions (Negishi and Drujan, 1979; Laufer and Salas, 1981). Our recent studies (Negishi et al., 1983; Teranishi et al., 1983) on photopic L-type horizontal cells in the carp retina have revealed that DA also restricts intracellu'ar LY to single injected cells, an effect, like that of DA on the S-potential, with which a dopaminergic blocker haloperidol interferes.

The present experiment with isolated carp retinas examined and quantitatively compared electrical and dye coupling areas between different classes of horizontal 
cells and explored the effects of DA and related compounds on the above phenomena.

\section{Materials and Methods}

Preparation, intracellular recording, and marking. Experiments were performed on isolated retinas of the carp (Cyprinus carpio). The fish (body length, 30 to $35 \mathrm{~cm}$ ) were dark-adapted for $1 \mathrm{hr}$ before enucleation to facilitate the separation of the retina from the pigment epithelium. The retina was isolated under dim red light and placed, receptor side up, in a transparent chamber through which humidified air was circulated at room temperature $\left(20\right.$ to $22^{\circ} \mathrm{C}$ ). In addition to normal retinas, a special preparation was used in which DA cells had been destroyed by intraocular injections of 6-hydroxydopamine $(6-\mathrm{OHDA}, 20 \mu \mathrm{g})$ plus pargyline $(20 \mu \mathrm{g})$ on 2 successive days 10 to 20 days before enucleation (Negishi et al., 1981, 1982). To tranquilize the isolated retinas from possible surgical disturbance and to let an applied chemical diffuse throughout the tissue, they were kept in darkness for 30 min before electrophysiological experiment.

Intracellular recordings were made by means of glass micropipettes filled with a $4 \%$ Lucifer Yellow $\mathrm{CH}$ (LY) dissolved in a $0.1 \mathrm{M}$ lithium chloride solution. A circular retinal area of $9.0 \mathrm{~mm}$ diameter, where the recordings were made, covered the central and intermediate regions surrounding the optic disc. The electrodes had a resistance of about 200 megohms. Cell penetration with a microelectrode was facilitated by producing oscillation of a preamplifier circuit, caused momentarily by excess positive feedback. Intracellularly recorded potentials were led into a high input impedance preamplifier (W-P Instruments $M$ 707) and were then exhibited on an oscilloscope and stored on an analogue magnetic tape. For illustration, the stored potentials were reproduced on a pen-recorder (San-ei Sokki 8S60). The dye (LY) was ionophoretically injected into a recorded cell with a sinusoidal current ( 4 cycles/sec) of $\pm 10 \mathrm{nA}$ for $30 \mathrm{sec}$.

Light stimuli. The isolated retina was stimulated by a light beam from a $500 \mathrm{~W}$ Xenon arc lamp. Monochromatic lights, $423,459,517,575,621$, and $674 \mathrm{~nm}$, were obtained by narrow-band interference filters in the path of the stimulating light beam. The size of a light spot on the retinal surface was variable from 0.25 to $4.0 \mathrm{~mm}$ in diameter. The intensity of light was attenuated by interposition of neutral density filters in the light path, covering a range of $4.0 \mathrm{log}$ units. All the monochromatic lights were equalized in quanta with a digital photometer (Tektronix J-16), and the unattenuated $(0 \mathrm{log})$ light beam, when brought to focus at the surface of the retina, was $8.3 \times 10^{12}$ quanta $/ \mathrm{cm}^{2}$ sec. The red $(621 \mathrm{~nm})$ light spot of $2.8 \mathrm{~mm}$ diameter at an intensity of $-1.5 \mathrm{log}$ units was usually used for central illumination during microelectrode penetration. To classify a recording cell, the stimulus wavelengths were varied from 423 to $674 \mathrm{~nm}$. Square wave pulses of light (1.0 sec duration) were produced by an electromagnetic shutter driven by logic circuitry and repeated at 4.0 -sec intervals. A light spot of $0.5 \mathrm{~mm}$ diameter was displaced in steps of $0.5 \mathrm{~mm}$ along a straight line of $4.0 \mathrm{~mm}$ in length, passing over a recording point at the middle. The changes in wavelength and in spot displacement were controlled automatically by independent switch systems. These recording and photostimulator systems were the same as those described in an earlier paper (Teranishi et al., 1982a).

Drug application. A small amount $(10 \mu \mathrm{l})$ of Ringer's solution containing DA plus pargyline (monoamine oxidase inhibitor) or related compounds ( 2 to $4 \mathrm{mM}$ ) was applied to the residual vitreous fluid beneath the isolated retina $30 \mathrm{~min}$ before the beginning of experiments, to try to maintain a relatively constant condition under drug action for 15 to $20 \mathrm{~min}$ during which the recordings were made. The wet weight of the preparations (retina plus residual vitreous fluid) was $180 \mathrm{mg}$ on the average. Thus, if the applied agent is assumed to diffuse evenly throughout the entire preparation, its concentration is 10 to 20 $\mu \mathrm{M}$ in the retina.

Histochemical procedure. After three to four cells were injected with LY in each preparation for 15 to $20 \mathrm{~min}$, the retinas were kept in darkness for $30 \mathrm{~min}$, fixed for several hours in a paraformaldehyde $(4 \%)$-sucrose $(35 \%)$ solution (FS solution), and then flat-mounted with the vitreal side facing up on a glass plate. After LY-marked cells were examined with half-dried flat mounts under a fluorescence microscope (Nikon EF), the preparations were softened again in the FS solution and then subjected to cryosection to $15 \mu \mathrm{m}$ thickness. The retinal sections were dried over Zeolite (Wako) in a desiccator for several hours, sealed with Entellan (Mcrck), and again cxamined under the fluorescence microscope. In this manner, LYmarked horizontal cells were seen in both flat mounts and cryosections of the same retinal preparations. The histochemical procedure has been described elsewhere (Negishi et al., 1983).

In fluorescence photomicrographs of flat mounts, each covering a retinal area of $0.18 \mathrm{~mm}^{2}$, the number of LYmarked cells was counted and the size of the dye diffusion area was measured by a weighing method. When numerous cells were stained, a few cells in the central part of a dye diffusion area were intensely fluorescent, while those in the peripheral area were pale and could be judged as only nuclei, which had a higher affinity for the dye than that of the perikarya. The counts included such nuclei as cells. The size of the dye diffusion area was estimated, covering probable dendritic fields of the cells, their nuclei only being visible. Since cellular fluorescence is relative to that of the background and depends on the amount of injected dye, which could not be precisely controlled in the present method, the obtained values for the number of marked cells and for the dye diffusion area are only approximate (Table I).

Classification of $S$-potentials. Light-induced responses ( $\mathrm{S}$-potentials) in the carp retina have been classified into five types: photopic and scotopic L-types and three Ctypes (Mitarai et al., 1974). The cells which are exclusively hyperpolarized by visible monochromatic lights are named L-type; photopic cells represent input signals mainly from red-sensitive cones, and scotopic cells reflect signals from rods. Among the C-types, the cells which are depolarized by red light and hyperpolarized by green are called RG-type; others, best depolarized by yellowgreen and hyperpolarized by both deep red and blue 
lights, are called YRB-type; and a third group which is depolarized by yellow-green and hyperpolarized by blue light is termed YB-type. In the present paper, however, the YB-type was grouped as the YRB-type, since both types showed similar behavior under certain experimental conditions (Kato, 1979).

According to Mitarai et al. (1974), horizontal cells located in the outermost layer generate the photopic Ltype response, those cells in the intermediate layer produce the RG- or YRB-type response, and those cells located in the innermost layer are the origin of the scotopic L-type response. In addition, the photopic Ltype as well as C-type responses can be recorded from a further proximal layer, where the axon terminals of different horizontal cells are identified by dye (Procian yellow) injection. The recording and marked depths of the above type responses in the present experiment well fit their description (Mitarai et al., 1974).

\section{Results}

Certain types of photopic S-potential were identified by their spectral response and later confirmed by morphological localization of the marked sites with LY. The recordings and LY-marked sites were correlated in each retinal preparation. Because of dye coupling between horizontal cells via gap junctions in a given cellular layer, the dye injected into a recorded cell was usually found to diffuse into several neighboring cells, as pointed out by others (Stewart, 1978; Kaneko and Stuart, 1980). When a cluster of several cell bodies in flat mounts was seen to stain with LY occasionally accompanied by the appearance of a weakly stained axon terminal, we judged that the response was being recorded from one of the cell bodies stained (Teranishi, 1983). On the other hand, if a few axon terminals were intensively fluorescent with the occasional appearance of a weakly stained cell body, we judged that the response was being recorded from one of the axon terminals stained (Teranishi, 1983). It was also certain during electrophysiological experiments that the responses from the soma were recorded at a level slightly distal to the level at which they could be obtained from the axon terminal. Although three to four cells were marked with LY in each preparation, approximately $80 \%$ of the stained sites (394) in 158 retinas could be retrieved in proper correspondence with the recordings. The marked sites at the axon terminal level $(n=78)$ were not considered in the present study, because the effects of DA were not consistent (Teranishi et al., 1983).

Selection of samples illustrated and used in quantitative comparison. For illustrations and quantitative comparison of samples, 6 to 16 representative recordings in each case were selected mainly on the basis of steadiness and regularity in recording. Irregular decay curves of response amplitude with spot displacement were observed in a few cases. At present, it is highly possible that they were due to distortion caused by surface conditions in the retinal preparation (e.g., presence of blood capillary, residual pigment epithelium, injured or waved surface in the illuminated spot), because some cells in the same point exhibited a similar irregularity in their decremental curves. These cases were omitted from the determination made. In all samples used, correlation between recordings and marked sites was firmly established.

$L$-type response. Representative recordings from the soma of L-type horizontal cells under different experimental conditions are illustrated in Figure 1. Rows 1, 2, and 3 are recordings from a normal retina, a retina treated with DA, and a retina in which DA cells had been destroyed by prior intraocular injection of 6-OHDA (DA cell-deprived retina), respectively. Columns $A, B$, and $C$ show spectral response to a $2.8-\mathrm{mm}$ diameter spot ( 423 to $674 \mathrm{~nm}$ ), incremental response amplitude with increasing diameter $(0.25$ to $4.0 \mathrm{~mm})$ of a red $(621 \mathrm{~nm})$ spot, and the decremental amplitude with stepwise displacement of a red $(621 \mathrm{~nm})$ spot $(0.5 \mathrm{~mm}$ diameter $)$. The same arrangements of representative recordings are made for RG-type (Fig. 3) and YRB-type responses (Fig. $5)$.

The amplitude of the peak response in the spectral curves (Fig. $1 \mathrm{~A}$ ) was $22.5,30.0$, and $14.4 \mathrm{mV}$ for normal, DA-treated, and DA cell-deprived retinas, respectively. The S-potentials recordable from DA cell-deprived retinas are relatively small in general in response to a 2.8 $\mathrm{mm}$ diameter spot at $-1.5 \log$ units.

As the spot diameter was increased from 0.25 to 4.0 $\mathrm{mm}$ (Fig. $1 B$ ), the response was monotonically enlarged. When the amplitude ratio of the largest response to the 4.0 - $\mathrm{mm}$ spot versus the smallest response to the 0.25 $\mathrm{mm}$ spot was calculated, it was found to be $11.1,4.3$, and 15.0 in normal, DA-treated, and DA cell-deprived retinas, respectively (Fig. 2). The values appear to indicate that the spatial summation is larger in the order of DA celldeprived, normal, and DA-treated retinas.

Amplitude decrement with spot displacement (Fig. 1C) was approximately exponential, showing maximum response at the center point $(0 \mathrm{~mm})$. The amplitude of the center response was increased but that of distant responses at $2.0 \mathrm{~mm}$ was decreased by DA, the decremental curve being sharpened (trace C2). In contrast, a lack of DA caused the opposite, the decremental curve being slowed (trace C3). The mean amplitude of the center response and the mean half-decay distance of the decremental curves, which were calculated in the three different preparations, are listed in Table I. The values indicate that the lateral spread of S-potentials was interfered with by DA but facilitated by the lack of DA.

It is interesting to point out that in general a transient of responses at the onset of light stimuli was sharpened (or increased) in DA-treated retinas (Fig. 1, trace 2) but slowed in DA-deprived ones (trace 3) as compared to that in controls (trace 1 ).

$R G$-type response. Figure 3 shows representative recordings of the same experimental procedures with RGtype horizontal cell bodies under the three different conditions (rows 1,2, and 3) as shown for L-type cells in Figure 1. For the amplitude increment with increasing diameter (column $B$ ) and the amplitude decrement with displacing spot (C), a 517-nm light was used, since it induced the largest hyperpolarizing response in the spectral curve $(A)$.

The effects of DA were found to be exactly the same as those described for I.-type responses. DA narrowed the summation area (trace B2) and shrank the lateral 
A<smiles>CC(C)Cc1ccccc1I</smiles>

2<smiles>CC=Cc1cc(C)cc(C)c1</smiles>

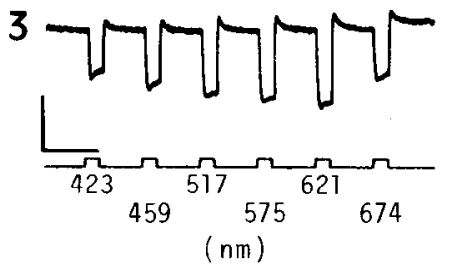

B
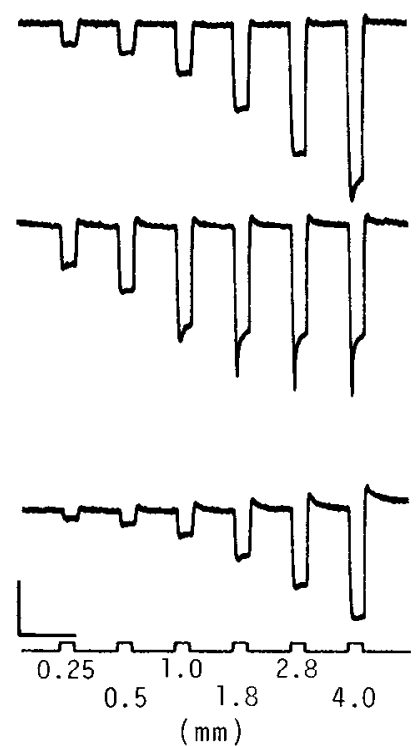

C
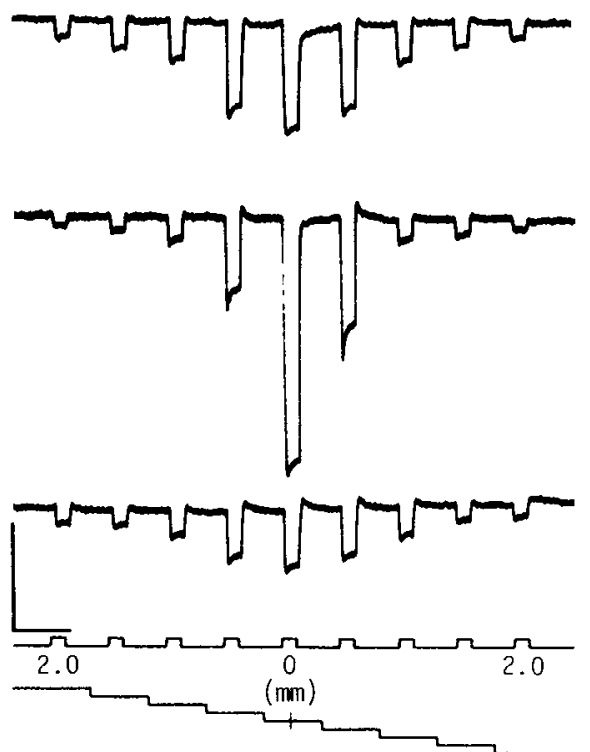

Figure 1. Representative recordings from photopic L-type horizontal cells in differently treated retinas. Column $A$, The spectral response to a $2.8-\mathrm{mm}$ diameter spot of monochromatic lights (from 423 to $674 \mathrm{~nm}$ ) at $-1.5 \log$ units (intensity). Column $B$, The amplitude increment with increasing diameter of a $621-\mathrm{nm}$ spot (from 0.25 to $4.0 \mathrm{~mm}$ ) at $-1.5 \log$ units. Column $C$, The amplitude decrement with displacement of a $621-\mathrm{nm} 0.5-\mathrm{mm}$ diameter spot $(-0.5 \mathrm{log}$ unit) in steps of $0.5 \mathrm{~mm}$ along a straight line of 4.0 $\mathrm{mm}$, the recording point being at the center $(0 \mathrm{~mm})$ of the displacement length. Recordings in row 1 are from a normal retina. Those in row 2 are from a retina treated with dopamine (DA, $20 \mu \mathrm{M}$ ). Those in row 3 are from a retina in which DA cells had been destroyed with prior intraocular injection of 6-hydroxydopamine (DA cell-deprived retina). The light stimulus and stepwise displacement signals are shown at the bottom traces, and the wavelength, diameter, and displacement distance are indicated. Scales: $10 \mathrm{mV}$ vertically and $4 \mathrm{sec}$ horizontally. In Figures 3 and 5, the arrangement of recordings and scales are the same as in this figure.

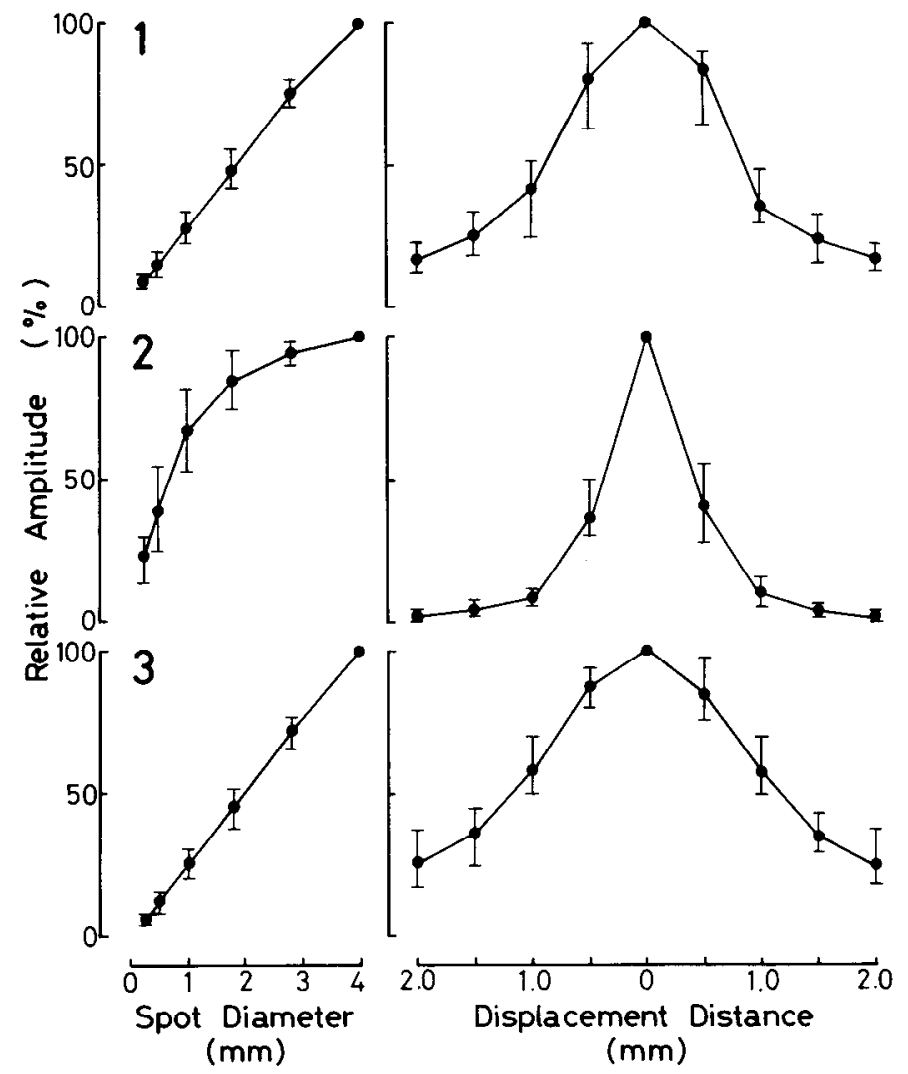

Figure 2. Graphic illustration of the amplitude increment of L-type horizontal cells with increasing spot diameter (left) and spread of S-potentials ( $C 2$ ), while the lack of DA produced the opposite effect (traces B3 and C3). This information is graphically presented in Figure 4 , and the mean values of the half-decay distance obtained from the different preparations are listed in Table I. It should be noted that the depolarizing response to $674 \mathrm{~nm}$ became smaller or obscure in both DA-treated (trace A2) and $D A$ cell-deprived retinas ( $A .3)$ than in normal ones $(A 1)$.

YRB-type response. Representative recordings obtained from YRB-type horizontal cells are collected in Figure 5, their normalized values are plotted in Figure 6 , and the mean values are listed in Table I. The effects of DA on these cells were fundamentally similar to those on the other types of cells described in Figures 1 and 3 . For the spectral response (column $A$ ) and the incremental amplitude $(B)$, the intensity of $-2.0 \mathrm{log}$ units was used, and in columns $B$ and $C$ (spot displacement) the wavelength used was $459 \mathrm{~nm}$, which induced the largest hyperpolarizing response in normal retinas (trace A1).

$L Y$-marked sites in different horizontal cells. Fluorescence photomicrographs in Figure 7 represent LY-

the amplitude decay with spot displacement ( right) in the three different preparations. The normalized mean values are obtained from representative recordings of 11 cells in normal retinas (row 1), 11 cells in DA-treated retinas (row 2), and 10 cells in DA cell-deprived retinas (row 3). Vertical lines indicate maximal deviations. In Figures 4 and 6 , the same arrangement of graphs was used for RG- and YRB-type cells. 
A

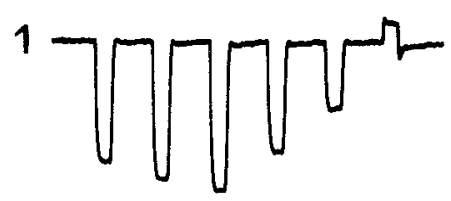<smiles>[2H]C(=C)CCCCC</smiles>

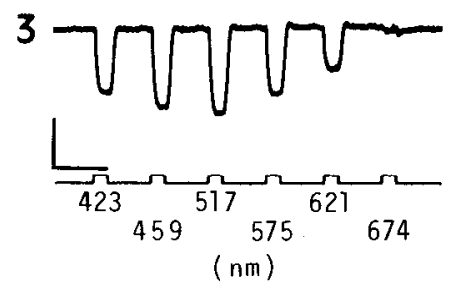

B

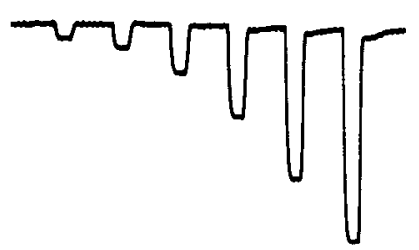

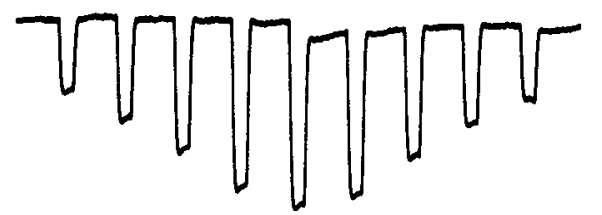

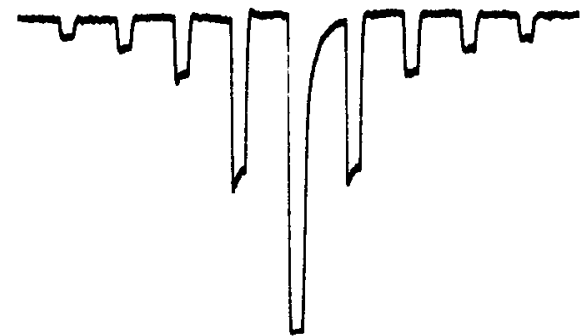

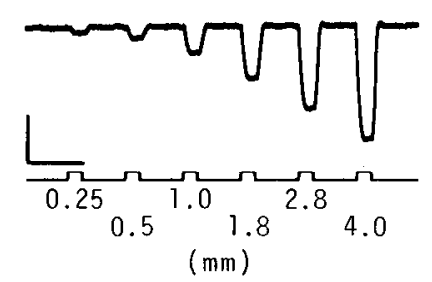

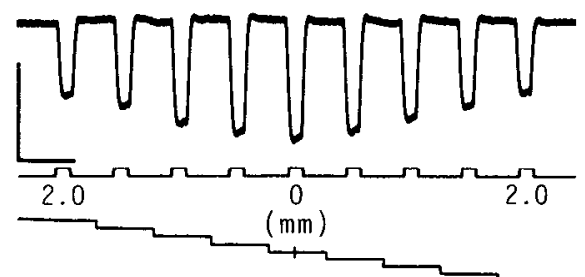

Figure 3. Representative recordings from RG-type cells in the three different preparations. The intensity used here was -2.0 $\log$ units for the spectral response (column $A$ ) and the amplitude increment (column $B$ ), and the wavelength used was $517 \mathrm{~nm}$ for the amplitude increment (column $B$ ) and the decrement (column $C$ ), because this wavelength produced the largest hyperpolarizing response in the spectral curves (column $A$ ). Otherwise, the experimental conditions were the same as those described in Figure 1.

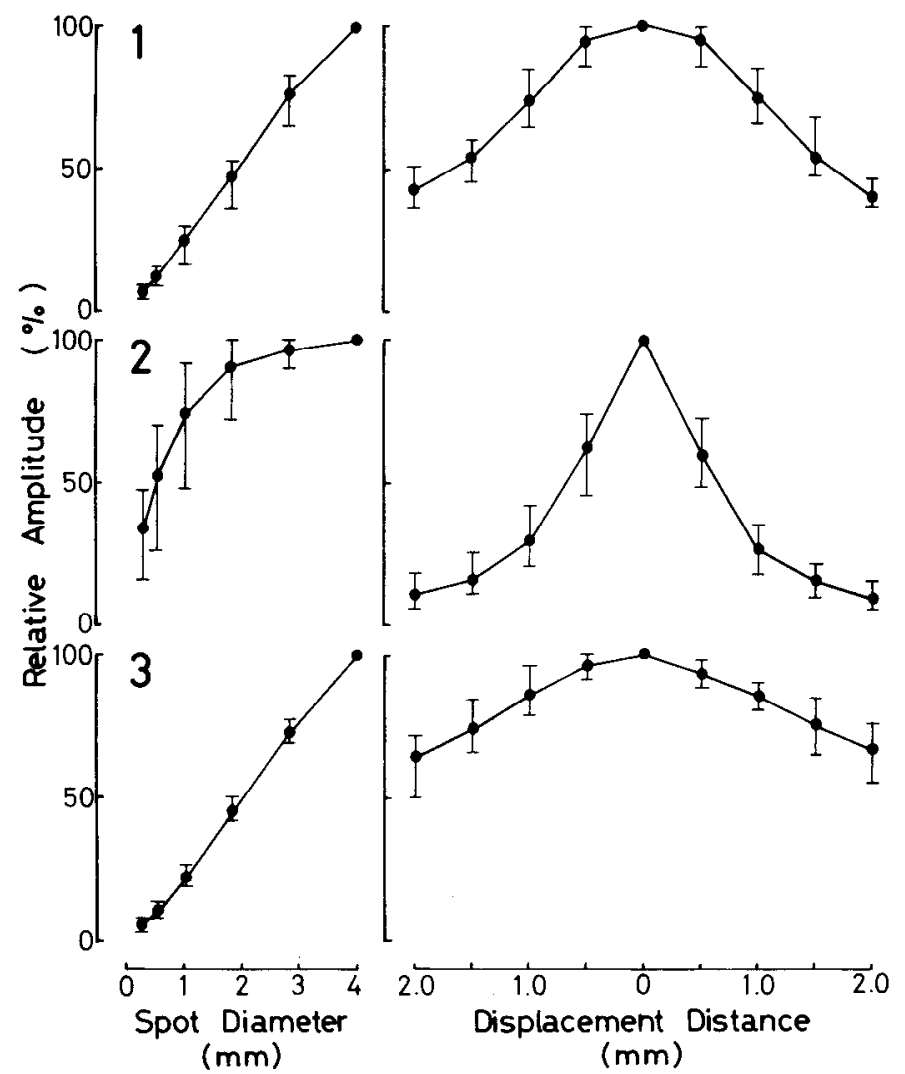

Figure 4. Graphic illustration of the amplitude increment (left) and the amplitude decay (right) of RG-type cells in the three different preparations. The number of samples was 16,8 , marked sites in three different types of horizontal cell under three different conditions. From the top row Ltype ( $A$ to $C$ ), RG- ( $D$ to $F$ ), and YRB-type cells ( $G$ to $I)$ are shown, and from the left column they are taken from normal ( $A, D$, and $G$ ), DA-treated $(B, E$, and $H)$, and DA cell-deprived retinas $(C, F$, and $I)$. It can be commonly pointed out through all types of cells that in normal retinas several neighboring cells are stained with LY, in DA-treated retinas only one cell is seen, and in DA cell-deprived retinas numerous cells are fluorescent. In any type of cells, DA restricted the dye to single injected cells, and the lack of DA tended to facilitate dye diffusion over a wider area than that seen in normal retinas.

Correlation between half-decay distance and dye diffusion area. Table I summarizes the data obtained, listing the values of the half-decay distance and the number of cells dye-coupled (diffusion area) in the three different preparations. The values of half-decay distances longer than $2.0 \mathrm{~mm}$ were estimated by extrapolation of the decay curves obtained for individual cells. A clear-cut correlation can be pointed out between the half-decay distance and the dye diffusion area. The half-decay distance is smaller in the order of L-, RG-, and YRB-type cells and in the order of DA-treated, normal, and DA cell-deprived retinas in a certain type. The diffusion area is smaller in the same order of cell types and retinal

and 9 cells in normal, DA-treated, and DA cell-deprived retinas, respectively. 
A<smiles>C=CCCC(=C)CC=CC</smiles>

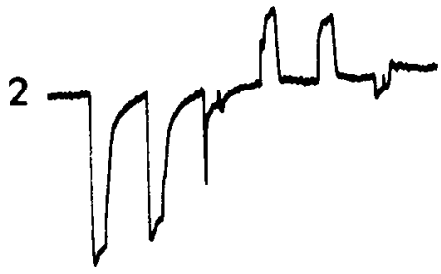

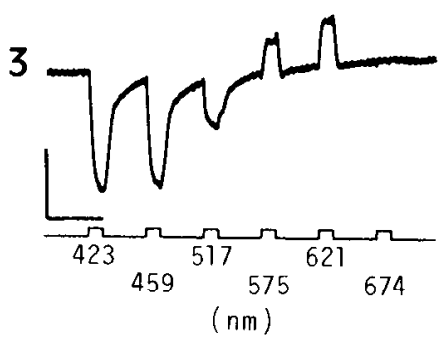

B
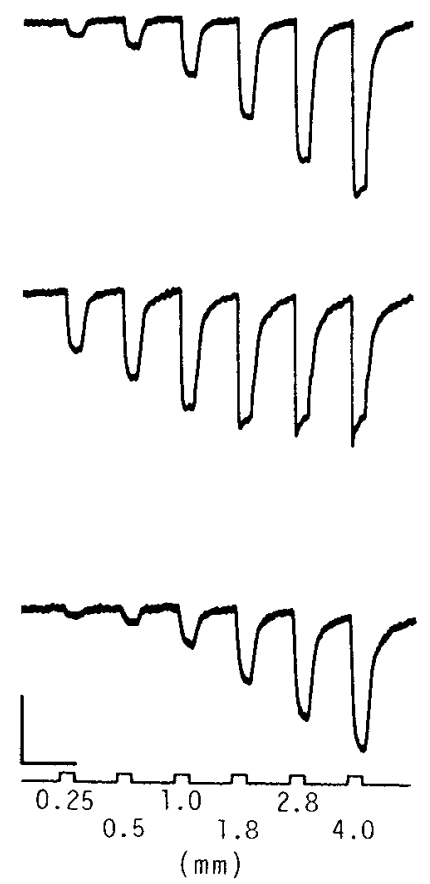

C
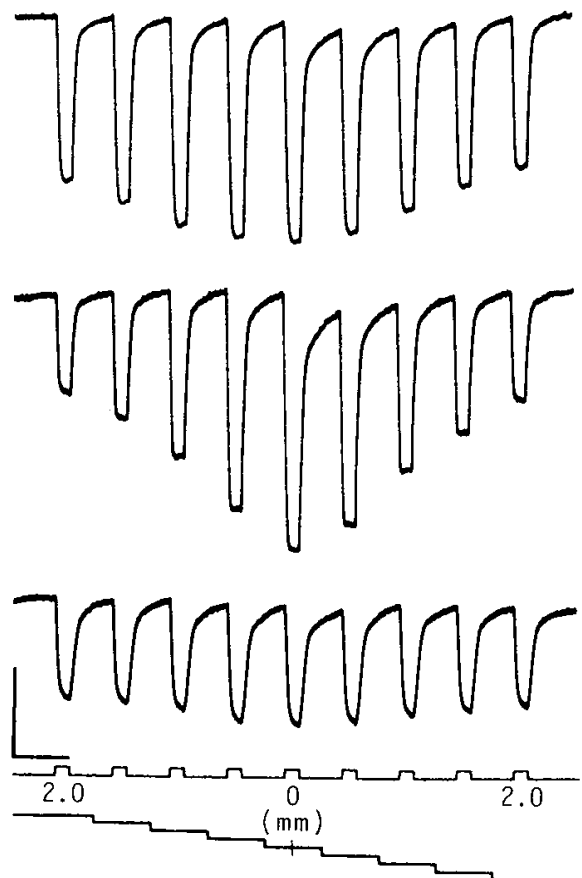

Figure 5. Representative recordings from YRB-type cells in the three different preparations. The wavelength used for the amplitude increment (column $B$ ) and for the amplitude decrement (column C) was $459 \mathrm{~nm}$, which induced the largest hyperpolarizing response in the spectral curve of normal retina (row 1 in column $A$ ). Otherwise, the experimental conditions were the same as those in Figure 3.

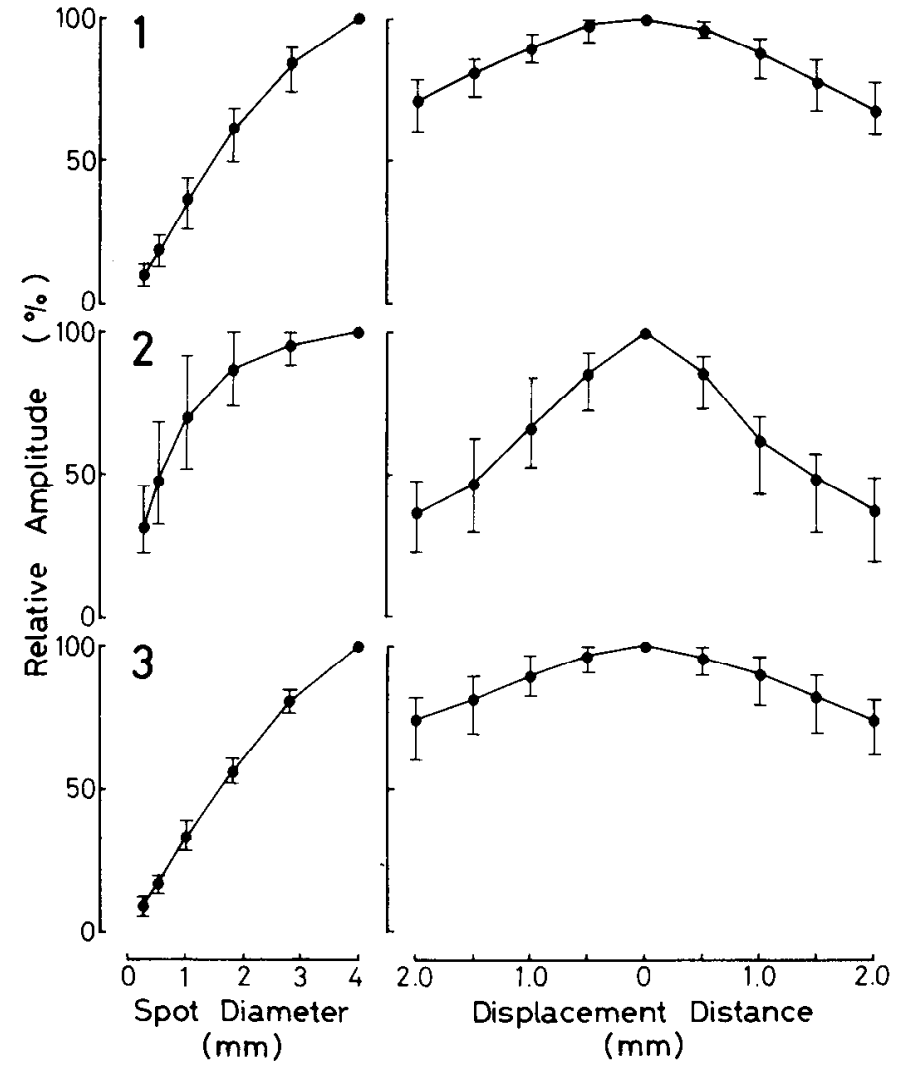

Figure 6. Graphic illustration of the amplitude increment (left) and decay (right) of YRB-type cells in the three different preparations, while the number of cells dye-coupled appears to be the same in the three types of cells under conditions already discussed. However, the number of all types of cells is about 2 -fold more in DA cell-deprived retinas than in normal ones.

Effects of DA-related compounds on horizontal cells. To avoid possible repetition of already illustrated cases with recordings and fluorescence photomicrographs, the effects of related compounds used in some of the present experiments will only be described. Our earlier papers (Negishi et al., 1983; Teranishi et al., 1983) described the effects of those agents on L-type horizontal cells. Prior treatment of the isolated retina with a dopaminergic blocker, haloperidol, tended to prevent the appearance of the DA effects on S-potentials and dye diffusion in all types of cells. Forskolin, dibutyryl cAMP, amphetamine, and bicuculline mimicked the effects of DA on all types of cells, narrowing the half-decay distance and restricting the intracellular dye to single injected cells.

\section{Discussion}

The present study was an extension of our earlier experiments (Negishi et al., 1983; Teranishi et al., 1983; Teranishi, 1983), in which we dealt with findings of only photopic L-type horizontal cells. Here, the results ob-

preparations. The number of samples was eight, six, and seven in normal, DA-treated, and DA cell-deprived retinas, respectively. 

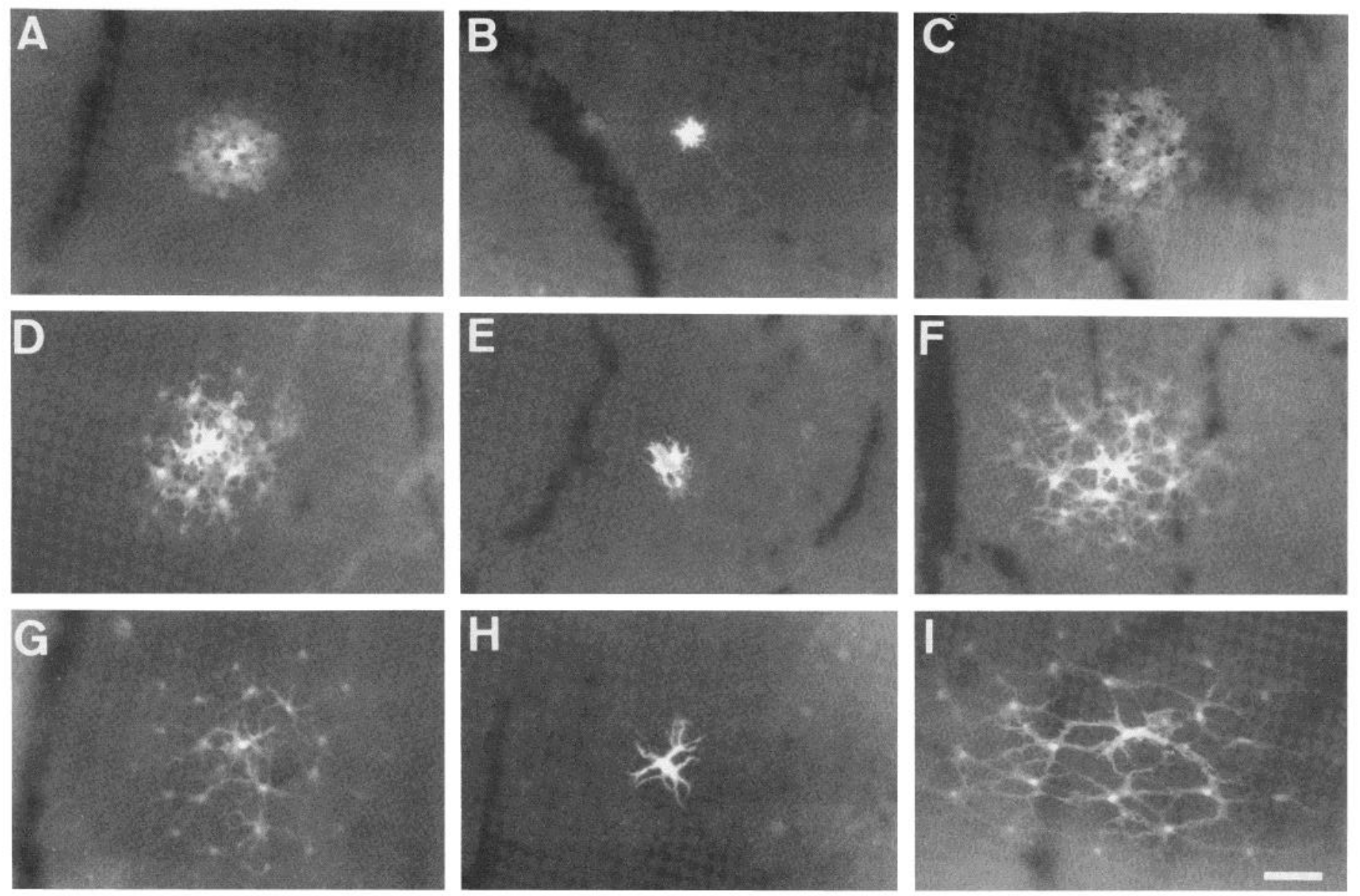

Figure 7. Fluorescence photomicrographs showing horizontal cells intracellularly marked with Lucifer Yellow (LY). $A$ to $C$ (top row), photopic L-type cells; $D$ to $F$ (middle row), RG-type cells; $G$ to $I$ (bottom row), YRB-type cells. $A, D$, and $G$ (left solumn), normal retinas; $B, E$, and $H$ (middle column), DA-treated retinas; $C, F$, and $I$ (right column), DA-cell deprived retinas. In $I$, the dye-coupling area of YRB-type cells exceeds in part the area illustrated, and the size of individual cells is certainly larger than those seen in $G$ and $H$. For each type of cells, the tendency seen with dye coupling in normal and DA cell-deprived retinas is the larger the cells the wider the diffusion area. Scale bar in $F, 50 \mu \mathrm{m}$.

TABLE I

Comparison of half-decay distance with dye-coupling area in the three different preparations

The samples of recording are the same as those used for graphs in Figures 2, 4, and 6, and the cell numbers (dye-coupling areas) are estimated from fluorescence photomicrographs corresponding to the recordings. The values listed are mean \pm SD.

\begin{tabular}{|c|c|c|c|c|c|c|}
\hline \multirow[t]{2}{*}{ Type } & \multicolumn{3}{|c|}{ Half-decay Distance (mm) } & \multicolumn{3}{|c|}{$\begin{array}{c}\text { Cell Number } \\
\left(\text { Dye Coupling Area } \times 10^{4} \mu \mathrm{m}^{2}\right)\end{array}$} \\
\hline & Normal & DA-treated & DA Cell-deprived & Normal & DA-treated & DA Cell-deprived \\
\hline $\mathrm{L}$ & $\begin{array}{l}0.9 \pm 0.1 \\
(n=11)\end{array}$ & $\begin{array}{l}0.4 \pm 0.1 \\
(n=11)\end{array}$ & $\begin{array}{l}1.2 \pm 0.1 \\
(n=10)\end{array}$ & $\begin{array}{c}12.5 \pm 3.1 \\
(1.05 \pm 0.10)\end{array}$ & $\begin{array}{c}1 \\
(0.08 \pm 0.01)\end{array}$ & $\begin{aligned} 23.9 & \pm 5.0 \\
(1.80 & \pm 0.34)\end{aligned}$ \\
\hline RG & $\begin{array}{l}1.6 \pm 0.1 \\
(n=16)\end{array}$ & $\begin{array}{l}0.7 \pm 0.1 \\
(n=8)\end{array}$ & $\begin{array}{l}2.5 \pm 0.3 \\
(n=9)\end{array}$ & $\begin{array}{c}13.7 \pm 2.1 \\
(2.93 \pm 0.40)\end{array}$ & $\begin{array}{c}1 \\
(0.19 \pm 0.03)\end{array}$ & $\begin{array}{c}25.6 \pm 4.5 \\
(4.50 \pm 1.26)\end{array}$ \\
\hline YRB & $\begin{array}{l}2.8 \pm 0.2 \\
(n=8)\end{array}$ & $\begin{array}{l}1.5 \pm 0.3 \\
(n=6)\end{array}$ & $\begin{array}{l}3.0 \pm 0.3 \\
(n=7)\end{array}$ & $\begin{array}{c}14.0 \pm 3.2 \\
(7.44 \pm 1.68)\end{array}$ & $\begin{array}{c}1 \\
(0.50 \pm 0.09)\end{array}$ & $\begin{aligned} 26.1 & \pm 3.7 \\
(12.79 & \pm 1.75)\end{aligned}$ \\
\hline
\end{tabular}

tained with different types of horizontal cell (photopic L-, RG-, and YRB-types) are presented: $(i)$ the spatial summation and the half-decay distance were smaller in the order of L-, RG-, and YRB-type cells; (ii) the dye diffusion area was smaller also in the same order; (iii) an application of DA narrowed the spatial summation, shortened the half-decay distance, and restricted the dye to single injected cells; $(i v)$ the deprival of DA cells from retinas produced the opposite; $(v)$ therefore, the spatial summation, half-decay distance, and the dye diffusion area were smaller in the order of DA-treated, normal, and DA cell-deprived retinas; and (vi) amphetamine, forskolin, and dibutyryl cAMP mimicked the effects of $\mathrm{DA}$, and a dopaminergic blocker, haloperidol, prevented the effects of DA and amphetamine on all types of horizontal cells.

A dye diffusion via gap junctions from an injected horizontal cell to neighboring cells in the retina appears to be time-dependent. In this respect, a series of control experiments is lacking from the present study. Before 
tissue fixation, however, all preparations were kept in darkness for $30 \mathrm{~min}$ after three to four cells were marked with LY during a 15 - to 20 -min experimental period. Furthermore, we have quantitatively compared as grouped samples the numbers of visible cells and dyediffused areas between three different types of horizontal cells and between three differently treated preparations. These procedures would minimize the time-dependent factor in the dye diffusion observed. The fact that the dye was found restricted within single injected cells in DA-treated retinas 30 to $50 \mathrm{~min}$ after injection indicates that the applied DA had continued to maintain its effect on horizontal cells for that period, because if the effect had faded away the dye would diffuse to neighboring cells as in control retinas.

In the present experiments with spot displacement, the intensity $(-0.5 \mathrm{log}$ unit) and diameter $(0.5 \mathrm{~mm})$ of light spot were kept constant for all types of cells to compare the degrees of the lateral spread in retinas under different conditions. The intensity used appeared to be adequate to induce a measurable amplitude of photopic L-type responses at $2 \mathrm{~mm}$ distance but to be high for the response of C-type cells. The spot size used $\left(\pi r^{2} \doteqdot 0.2\right.$ $\mathrm{mm}^{2}$ ) was certainly wider than the dendritic field of individual cells $\left(1\right.$ to $\left.7 \times 10^{-3} \mathrm{~mm}^{2}\right)$ and than a dyecoupling area of YRB-type cells (about $0.13 \mathrm{~mm}^{2}$ ) in DA cell-deprived retina (see Table I). If the intensity, diameter, or both are reduced, shorter half-decay distances can be obtained for each type of cells. Therefore, the degrees of half-decay distance and of dye diffusion are dependent upon various experimental parameters, and all of the values listed in Table I are relative and valid in comparison under the present experimental conditions.

Intracellular recordings of responses were made from a circular area of the retina $(9.0 \mathrm{~mm}$ in diameter $)$, covering the central and intermediate regions. In general, and common in all three types of cells, the cell size appears to be larger in the intermediate region than in the central region (surrounding the optic disc). According to the estimated values listed in Table $I$, a visualized area with LY involves a comparable number of cells stained13 to 14 cells in normal retinas and 24 to 26 cells in DA cell-deprived retinas, regardless of cell types. Therefore, the dye-coupling area appears to be determined by the size of individual cells or by the number of gap junctions. There have been found a wider receptive field and dyecoupling area between axon terminals than those between the somata of carp horizontal cells (Teranishi, 1983). However, the effects of DA on the receptive field and dye coupling at the terminal level have been shown to be inconsistent (Teranishi et al., 1983). In the catfish retina, when DA is applied in a jet form through a nebulizer onto the eye-cup preparations, it produces a marked effect on somal S-potentials similar to that on carp somal potentials but has little effect on axonal ones (E. Hida, K. Negishi, and K. -I. Naka, personal communication). These findings suggest that gap junctions between horizontal cell axon terminals may differ in nature from those between the somata, at least the former being not regulated by DA in the fish retina.

Dopamine-containing (DA) cells in the fish retina belong to a class of interplexiform cells which extend their processes toward both the outer (OPL) and inner plexiform layers (IPL). The processes of the DA cells have mutual synaptic contacts between amacrine cells in the IPL and are presynaptic to external (photopic Ltype) horizontal cells and bipolar cells in the distal level of the inner nuclear layer (Dowling and Ehinger, 1975). Therefore, the DA cells are assumed to provide a centrifugal pathway from the IPL to the OPL (Dowling and Ehinger, 1975, 1978), and the effects of exogenously applied DA on photopic L-type horizontal cells may simulate a function of DA interplexiform cells. In fact, DA was found not to cause any effect on the membrane potential of C-type cells in the goldfish retina (Hedden and Dowling, 1978). However, in earlier experiments (Negishi and Drujan, 1978, 1979), when DA was applied to isolated retinas of the mojarra (Eugerres plumieri) in the perfusate, the reciprocal effects of DA were found on all types of S-potential, increasing the center response to spot while decreasing the surround response to annular illumination. The present experiments confirmed these earlier findings and correlated the DA-induced shrinkage of the receptive field with restricted dye diffusion to single injected cells.

On the basis of the above EM observations (Dowling and Ehinger, 1975), the effects of DA on L-type horizontal cells, described in the present report, can be understood as a direct action of DA on the cell membrane, probably increasing its resistance wholly at gap junctions. Although similar effects of DA on all C-type horizontal cells are hard to explain at present, these are undoubtedly mediated by the same mechanism as in Ltype cells, because the dye diffusion was restricted by DA and facilitated by the lack of DA in both RG- and YRB-type cells. Prior treatment of isolated retinas with a dopaminergic blocker, haloperidol, tended to prevent the appearance of the DA effects on S-potentials and dye diffusion in all types of cells.

It is known that in the retina DA stimulates adenylate cyclase, the enzyme which synthesizes cAMP from ATP (Brown and Makman, 1972; Watling and Dowling, 1981). The effects of DA on horizontal cells are assumed to be mediated by the activation of DA-sensitive adenylate cyclase in the horizontal cell membrane (Van Buskirk and Dowling, 1981). Dibutyryl cAMP, similarly applied to the carp retina, produced the same effects as DA. An adenylate cyclase stimulator, forskolin, also mimicked the DA effects. The application of DA, dibutyryl cAMP, and forskolin to DA cell-deprived retinas restored the normally observed effects of these drugs on horizontal cells (Negishi et al., 1983; Teranishi et al., 1983). The observations strongly indicate that DA exerts its uncoupling action on horizontal cells through a DA receptormediated mechanism in the cell membrane. Perhaps a small percentage of dopaminergic processes contact Ctype horizontal cells, although they have not been described (Dowling and Ehinger, 1975). Alternatively, it is possible that there are nonsynaptic DA receptors on Ctype cells.

In the turtle retina (Neyton et al., 1982; Piccolino et al., 1982), GABA antagonists (bicuculline and picrotoxin) as well as DA have been found to produce effects 
on L-type horizontal cells similar to the DA effects on carp horizontal cells. The turtle DA cells belong to a subset of amacrine cells (differing from the interplexiform cell type in the carp) and do not synapse with Ltype horizontal cells. In the carp retina, bicuculline has been shown to exert its uncoupling action on horizontal cells through DA cells (Negishi et al., 1983). Although this is assumed to be the case in the turtle retina, the mechanism underlying the DA effects on turtle L-type horizontal cells, as well as on carp C-type horizontal cells, does not materialize at present.

In general, a transient response at the onset of light stimuli was found sharper in DA-treated retinas (trace 2 in Figs. 1, 3, and 5) and slower in DA cell-deprived ones (trace 3) than in controls (trace 1). Such transients are usually attributed to feedback from horizontal cells to cones (Stell and Lightfoot, 1975). DA would facilitate such feedback within an illuminated area, because the responses to central spots were markedly enlarged in amplitude, although distant responses were reduced in DA-treated retinas. The spectral response of RG- and YRB-type cells apeared to be somewhat different in differently treated retinas. For instance, the depolarizing response of RG-type cells to a 674-nm spot was smaller in DA-treated and DA cell-deprived retinas than that in normal ones (Fig. 3). The hyperpolarizing response of YRB-type cells to the deep red spot was larger in DAtreated retina but disappeared in DA cell-deprived retina (Fig. 4). Furthermore, the response of YRB-type cells to $517 \mathrm{~nm}$ was variable under different conditions, and the largest hyperpolarizing response was seen to $423 \mathrm{~nm}$ in DA-treated and DA cell-deprived retinas (Fig. 4). In such preparations, some alteration in feedback signals from horizontal cells to cones might be responsible for changes in the spectral response of C-type cells. However, the degree of these changes varied from cell to cell recording and could not be quantitatively treated.

The different appearance of networks in the three types of horizontal cells of the carp retina was first demonstrated here by dye (LY) coupling in flat mounts. In the same retina, scotopic L-type horizontal cells showed a smaller area summation (Teranishi et al., 1982a) and less dye coupling than those of photopic-type horizontal cells. The latter information was obtained in the present experiments, although the data were not dealt with because only a small number of scotopic Ltype cells was examined. In normal retinas, one scotopic L-type cell was marked by intracellular LY, exhibiting poor dye coupling between those cells. Even in DA celldeprived or haloperidol-treated retinas, a few cells of the scotopic L-type could be stained. The same marking technique was applied to horizontal cells of the lamprey (Lampetra japonica) (Teranishi et al., 1982b); one cell was found to be marked, suggesting poor dye coupling between cells. In the rabbit (Dacheux and Raviola, 1982) and cat retina (H. -A. Saito, personal communication), axonless horizontal cells showed a wide receptive field and dye-coupling area, whereas those bearing an axon exhibited a narrow field with no dye coupling. Therefore, an apparent correlation between the receptive field and the LY-coupling area appears to be common in vertebrate horizontal cells.

\section{References}

Brown, J. H., and M. H. Makman (1972) Stimulation by dopamine of adenylate-cyclase in retinal homogenates and of adenosine $3^{\prime}, 5^{\prime}$-cyclic monophosphate formation in intact retina. Proc. Natl. Acad. Sci. U. S. A. 69: 539-543.

Cohen J. L., and J. E. Dowling (1983) The role of the retinal interplexiform cell: Effects of 6-hydroxydopamine on the spatial properties of carp horizontal cells. Brain Res. 264: 307-310.

Dacheux, R. F., and E. Raviola (1982) Horizontal cells in the retina of the rabbit. J. Neurosci. 2: 1486-1493.

Dowling, J. E., and B. Ehinger (1975) Synaptic organization of the amine-containing interplexiform cells of the goldfish and cebus monkey retina. Science 188: 270-273.

Dowling, J. F., and B. Fhinger (1978) The interplexiform cell system. I. Synapses of the dopaminergic neurons of the goldfish retina. Proc. R. Soc. Lond. Biol. 201: 7-26.

Hedden, W. L., and J. E. Dowling (1978) The interplexiform cell system. II. Effects of dopamine on goldfish retinal neurons. Proc. R. Soc. Lond. (Biol.) 201: 27-55.

Kaneko, A. (1971) Electrical connections between horizontal cells in the dogfish retina. J. Physiol. (Lond.) 213: 95-105.

Kaneko, A., and A. E. Stuart (1980) Coupling between horizontal cells in the carp retina examined by diffusion of Lucifer Yellow. Biol. Bull. 159: 486.

Kato, S. (1979) C-type horizontal cell responses to annular stimuli. Exp. Eye Res. 28: 627-639.

Laufer, M., and R. Salas (1981) Intercellular coupling and retinal horizontal cell receptive field. Neurosci. Lett. Abstr., 7: $\mathrm{S} 339$

Marmarelis, P. Z., and K. -I. Naka (1972) Spatial distribution of potential in a flat cell. Application to the catfish horizontal cell layers. Biophys. J. 12: 1515-1532.

Mitarai, G., T. Asano, and Y. Miyake (1974) Identification of five types of S-potential and their corresponding generating sites in the horizontal cells of the carp retina. Jpn. J. Ophthalmol. 18: 161-176.

Naka, K. -I., and W. A. H. Rushton (1967) The generating and spread of S-potential in the fish (Cyprinidae). J. Physiol. (Lond.) 192: 437-461.

Negishi, K., and B. D. Drujan (1978) Effects of catecholamines on the horizontal cell membrane potential in the fish retina. Sens. Processes 2: 388-395.

Negishi, K., and B. D. Drujan (1979) Effects of catecholamines and related compounds on horizontal cells in the fish retina. J. Neurosci. Res. 4: 311-334.

Negishi, K., T. Teranishi, and S. Kato (1981) Similarity in spatial distribution between dopaminergic cells and indoleamine-accumulating cells of carp retina. Acta Histochem. Cytochem. 14: 449-460.

Negishi, K., T. Teranishi, and S. Kato (1982) Neurotoxic destruction of dopaminergic cells in the carp retina revealed by a histofluorescence study. Acta Histochem. Cytochem. 15: 768-778.

Negishi, K., T. Teranishi, and S. Kato (1983) A GABA antagonist bicuculline exerts its uncoupling action on external horizontal cells through dopamine cells in carp retina. Neurosci. Lett. 37: 261-266.

Neyton, J., M. Piccolino, and H. M. Gerschenfeld (1982) Dopamine (DA) and drugs that increase intracellular cyclic AMP decrease junctional communication between L-horizontal cells. Neurosci. Lett. Abstr. 8: 132.

Norton, A. L., H. Spekreijse, M. L. Wolbrasht, and H. G. Wagner (1968) Receptive field organization of the S-potential. Science 160: 1021-1022.

Piccolino, M., J. Neyton, P. Witkovsky, and H. M. Gerschenfeld (1982) $\gamma$-Aminobutyric acid antagonists decrease junc- 
tional communication between L-horizontal cells of the retina. Proc. Natl. Acad. Sci. U. S. A. 79: 3671-3675.

Stell, W. K., and D. O. Lightfoot (1975) Color-specific interconnections of cones and horizontal cells in the retina of the goldfish. J. Comp. Neurol. 159: 473-502.

Stewart, W. (1978) Functional connections between cells as revealed by dye-coupling with a highly fluorescent naphthalimide tracer. Cell 14: 741-759.

Teranishi, T. (1983) Lateral spread of light-induced response at the cell body and axon terminal levels of external horizontal cells in the carp. Jpn. J. Physiol. 33: 417-428.

Teranishi, T., S. Kato, and K. Negishi (1982a) Lateral spread of S-potential components in the carp retina. Exp. Eye Res. 34: $389-399$

Teranishi, T., K. Negishi, and S. Kato (1982b) Two types of light-induced response recorded from horizontal cells in the river lamprey retina. Neurosci. Lett. 33: 41-46.

Teranishi, T., K. Negishi, and S. Kato (1983) Dopamine modulates S-potential amplitude and dye-coupling between external horizontal cells in the carp retina. Nature 301: 243246.

Tomita, T., T. Tosaka, K. Watanabe, K., and Y. Saito (1958) The fish EIRG in response to different type of illumination. Jpn. J. Physiol. 8: 41-50.

Van Buskirk, R. G., and J. E. Dowling (1981) Isolated horizontal cells from carp retina demonstrated dopamine-dependent accumulation of cyclic AMP. Proc. Natl. Acad. Sci. U. S. A. 78: 7825-7829.

Watling, K. T., and J. E. Dowling (1981) Dopaminergic mechanisms in the teleost retina. I. Dopamine-sensitive adenylate cyclase in homogenates of carp retina; effects of agonists, antagonists and ergots. J. Neurochem. 36: 559-568. 